\title{
Why the Resistance: Minimally Invasive Pancreaticoduodenectomy-Saving the Patient from Tigers
}

\author{
Brij B Agarwal $^{1} \cdot$ Chintamani $^{2} \cdot$ Neeraj Dhamija $^{1} \cdot$ Shruti Sharma $^{3} \cdot$ Sneh Agarwal $^{4}$
}

Received: 10 December 2016 / Accepted: 10 December 2016/Published online: 13 December 2016

(C) Association of Surgeons of India 2016

When a man attacks tiger, he calls it sport; when a tiger attacks him, he calls it ferocity

- George Bernard Shaw

Pancreas has been called a "Hermit Organ", Paradoxically Sir Andrew Wattkay named pancreatic resection as akin to surgical venturing into "Tiger Country" [1]. The aim of pancreatic resection is to improve the well being of a suffering patient. The patient seems only a play field for either the "Tiger Surgeon" attacking the "Tiger pancreas" as a sport or the ferocious "Tiger pancreas" challenging the "Tiger surgeon". A recent play by Nina Raine seems to have defined the surgical term "Tiger country", rather well. "For a surgeon, tiger country is when you have to stick a knife in a patient close to a vascular post, knowing that one slip will cause death" [2]. The play was appreciated as a reflection of

Chintamani

drchintamani7@gmail.com

1 Department of General and Laparoscopic Surgery, Ganga Ram Institute of Post Graduate Medical Education and Research (GRIPMER), New Delhi, India

2 Department of Surgery VMMC, Safdarjang Hospital, New Delhi, India

3 Department Of Surgery, Harlem Hospital Center, New York, NY, USA

4 Department of Anatomy, Lady Hardinge Medical College, New Delhi, India modern day surgical theaters, reiterating the balance between surgical tigerhood and primacy of focus on our patients [3]. Progress in surgery has been driven by a pleothera of goals with the goal post of improving patient reported outcomes (PRO) $[4,5]$. In this technology driven era of tech wielding surgeon, web enabled safety conscious patient, hybridization of technologies, gender neutralization in ORs, the PROs have moved towards zero tolerance of adverse outcomes [6-13]. The march of heightened expectations of PROs have been enthusiastically matched by the advances in minimally invasive surgery (MIS). The popularity and professional acceptance of MIS came ahead of evidence from well designed studies. The march of MIS since first laparoscopic cholecystectomy by Eric Muhe in 1986 has been very impressive [14]. The MIS techniques have become standard care for many gastrointestinal malignancies (GIM), building upon the experience of MIS colectomies $[15,16]$. The clinical equivalence in terms of oncological integrity, fast track protocol compliance, PROs, survival benefits and MIS reproducibility have been established in the index GIM [17, 18]. Assimilation of Pancreaticoduodenectomy (PD) into MIS repertoire has been slow as evident from reports of only $4 \%$ PDs being done by MIS, in decade long US data base volume of more than 15,000 PDs [19]. Apart from the 'learning proficiency curve' (LCP) issues, this slow adoption of minimally invasive PDs (MIPD) is attributable to the retroperitoneal location of pancreas, its proximity to major vessels, prevalence of aberrant major vessels, and propensity for major postoperative complication [19]. There is hope, as high impact studies about MIS in different surgical anatomies have plateaued for cholecystectomy while being increasingly published for GIMs as shown in Fig. 1 [20]. Among the GIM related MIS publications, there is an encouraging trend in MIPD publications as 


\section{MIS Publications Per Site}

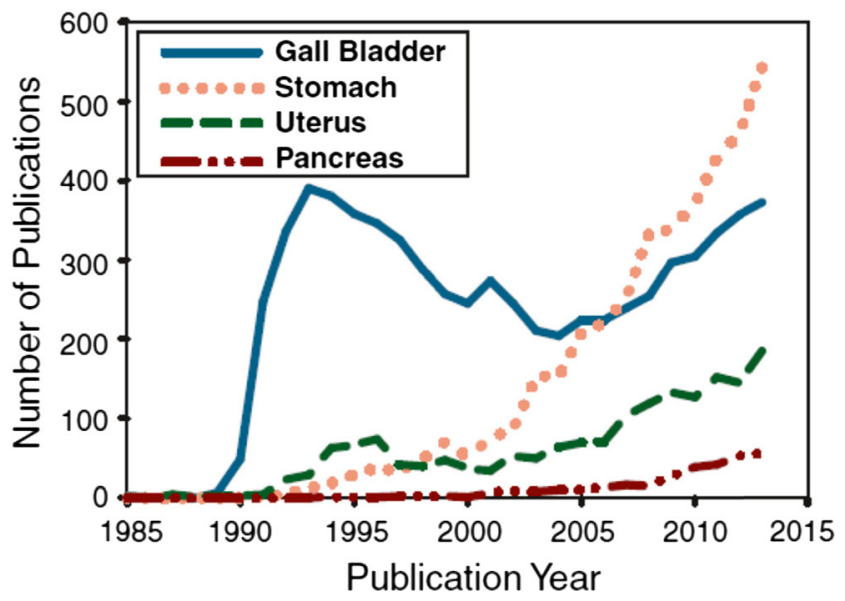

Fig. 1 MIS publications per site

shown in Fig. 2 [20]. Recent advances have improved the quality of care for patient suffering from a still unsolved problem of pancreatic cancer. Some of these advances are [21]:-

1. Advances in imaging technique to precisely define the resectability and charting out the surgical navigation with a previsualized vascular road map.

2. Advances in neoadjuvant therapies to improve not only the pool of resectable pancreatic cancers, but also enhance progression free survival with potential disease free survival.

3. Advances in understanding molecular biology of pancreatic cancer led promises of gene based targeted therapies.

These improvements in prospects of pancreatic cancer are augmented with timely administered and noncompliance free, adjuvant therapies. Faster convalescence, recovery in a

\section{Cancer-Related}

\section{MIS Publications Per Site}

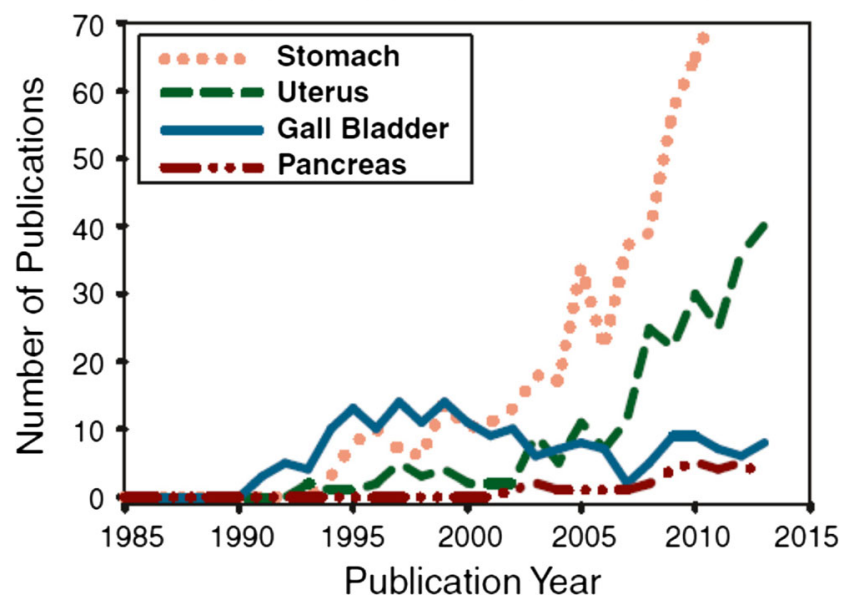

Fig. 2 Cancer-related MIS publication per site timelier manner and minimized wound related morbidity concerns, are the additional benefits of MIPD, that can ensure a totally compliant, timely institution of adjuvant therapy [22]. This can go a long way in building upon the advantages listed above. If that be so, what are the reasons for only 4\% PDs being performed by MIS even in most advanced surgical centers?

Successful MIS intrusion into different surgical domains has to take the steps of feasibility, efficacy, clinical equivalence, non inferiority in terms of complications, costs, superiority of PROs/clinical benefits and reproducibility for final universal adoption. The gain in surgical wisdom, in a decade of MIPD, has established all the required steps for the staircase for universal navigation of PD towards MIPD [19, 20, 22]. The phrase "Tiger country" explains the fraternity driven appropriation of a self exalted pedestal of pancreatic surgery. Pancreatic surgery though a part of general surgical repertoire has been made a hand maiden of a seclusive club. This approximation has been advocated on principles of high volume surgeon/centres for PDs. A recent global survey has bared the tiger fangs, exposing the cultivated volume myth. The survey involving 22 international gastrointestinal societies found that the tiger surgeon performs a median of $12 \mathrm{PDs} /$ year in a median career total of 80 PDs. With half of them having career total volume less than the number of PDs recommended for learning curve. There is a contrast between "the practiced" and "the preached" vis a vis oft touted and established randomized evidence [23]. Pancreatic resection, whether in PD or MIPD revolves around a structured, stepwise charting in the surgical tiger country. It requires a safe, anatomically precise dissection, away from major vascular zones, to resect the right pancreas, along with the "distal stomach - duodenum choledochus" complex. The resection is followed by reconstruction to restore the gastrointestinal and hepato-intestinal continuities. Safety of precise dissection based oncoresection is premised on anatomical holy planes, first described in context of rectal malignancies [21]. In developing these anatomical holy planes for safe surgical navigation, Heald defined three basic principles -

1. Exploration and exploitation of mobility between tissues of different embryological origins.

2. Good illumination enabled, direct vision guided, sharp dissection

3. Assistance provided continuous "traction - countertraction" without any actual tearing to gently open these planes.

The planes between endodermal pancreas and mesodermal vascular channels are thus MIS friendly. Pancreas develops as a twin outpouching of endoderm lying in contiguous developmental proximity to stomach, duodenum and common bile duct (CBD). While the dorsal portion forms most of the pancreatic head, the ventral outpouching gets 
carried by the CBD rotation to remain as the uncinate process. These embryological contiguities and selective rotation explain the mandatory enblock resection in PD with the challenge of dealing with dissection of the rotation wanderer uncinate. The portal vein and its configuration develops from distinct segments of vitelline veins. Given these different embryological origin, there is a distinct navigational plane to be explored as defined above. Exploration of these dissection planes in a safe avascular manner has already been shown to be MIS friendly [24-28]. These advantages are especially helpful in situation with anatomical aberrations [27]. Enhanced vision, better illumination, magnified visual projections of the directly targeted surgical field are already established virtues of MIS. It has allowed surgical adventures in closed, anatomical zones where there are no natural planes like breast and retroperitoneum too [28-30].

Final dictum of safe precise dissection is 'tractioncountertraction' play. In conventional PD, a significant muscle cutting parietal wound is necessary which needs constant retraction. This constant traction drains the assistance energies, deployed at the parietes, rather than helping in dynamic traction - countertraction assistance at the pancreatic resection interface. In MIS these dynamic capabilities are enhanced by deploying the instrument/assistant ergonomics directly at the dissection interfaces.

Thus, MIS respects all the three attributes of surgical navigation required for resection in MIPD. The next challenge in MIPD is the reconstruction that entails various anastomosis. The accumulated experience of MIS in GIM and MIS bariatric surgeries have made the reconstruction required in MIPD an extension of these skills.

Incorporating all these unique facilitative virtues of MIS in MIPD, the only concern seems to be that of taxing duration of surgery being less than adequately rewarding to the psychology of practicing MIS surgeon. Advent of MIS was lapped by us as a leash provided to dying opportunities in general surgery. Practicing fraternity rode the bandwagon of MIS popularity and got accustomed to comfort zone of adequate rewards for a few hour commitment on the table. Even in conventional PD the duration and the fatigue has been a major deterrent for its universal presence in general surgery lists. The advent and ascent of MIS coincided with establishment of specialized gastrointestinal surgical departments (GIS). The adoption of MIS and branching into the GIS started as synchronous and parallel streams to follow for the restless, creative amongst the then surgical pool. Those opting for GIS, channelized their entire energies towards establishment of the distinct GIS identify. It resulted in an early handicap on not being incrementally skilled in MIS. The PD moved into the lap of GIS and was ignored by MIS enthusiasts for better reward ratios, depriving PD of the unimaginable MIS advantages. The MIS enthusiastic were named "Boys with toys".
They have matured with toys performing the resection/ restoration procedures [31]. The general surgeon who adopted MIS incrementally into his repertoire from cholecystectomy - ventral hernias - inguinal hernias - solid organ removal - gastrointestinal resection/anastomosis, is not only adequately skilled for MIPD, but also psychologically equipped for the surgical surprises over the long haul of MIPD. The general surgeon in his forties or fifties (the median age of global PD surgeon being 45 year) [23] started out with the bandwagon of MIS in late 1980 or early 1990s. He is not only skilled to navigate MIPD march but also able shouldered to hold the "Mother Church" of surgical disciplines i.e. General Surgery [31]. This endeavor of MIPD is being assisted by our collaboration with colleagues across different medical domains [32]. The lack of MIS pursuit amongst the practicing GI surgeons and lack of being trained for MIPD has been recognized as a major concern [33]. Addition of Robotic capabilities to MIS has improved the precision in dissection, simplified anastomotic suturing and removed technical compromises and 'surgeon fatigue related' concerns [34]. Apart from the PRO based and gross oncological gains of MIPD, MIS has shown to reduce the biomolecular inflammatory response to surgery including the heapto-biliary molecules [35-37]. Surgery causes immunosuppression, as well suppression of tumor suppressive factors (like Insulin like growth factor binding protein 3; IGFBP-3) [18, 38]. These biomolecular and immunosuppressive cascades are attenuated in MIS. Hence the advantages of MIPD on immunosuppressive front are incremental. The ability to record the entire surgical detail in continuity is a, learning tool, as a rewind tool for need of postoperative hindsight and also fulfills upcoming medicolegal necessity $[39,40]$. Surgical navigation in MIPD will eventually become friendly for a holistically trained surgeon guided by Imagineering and treading the innovation prone MIS routes, augmented by supra 'holy plane' mentation, keeping it simple and safe (KISS) [41-44]. This has already been successful in a Natural Orifice Specimen Extraction (Trans Vaginal) in our female patients undergoing MIPD, further reducing the postoperative waiting period for adjuvant therapies [45-47]. Evidence will gradually accumulate. The experience of general surgery training, based upon BISS (Because I said so [46]) will carry the MIS enabled general surgeon in KISS navigations of MIPD. The principles of MIS with BISS and philosophy of KISS will save the patient from the surgical turf wars, as well as the supremacy tussle between the "Tiger surgeon" and the "Tiger pancreas".

\section{References}

1. McClusky DA 3rd, Skandalakis LJ, Colborn GL, Skandalakis JE (2002) Harbinger or hermit? Pancreatic anatomy and surgery through the ages - part 1. World J Surg 26(9):1175-1185 
2. Raine N (2014) Tiger country (NHB Modern Plays) Published by Nick Hern Books, the Glasshouse, 49a Goldhawk Road, London W12 8QP; Reprint edition (11 Dec 2014)

3. https://www.theguardian.com/stage/2014/dec/16/tiger-countryhampstead-theatre-review. Accessed on 21 Aug 2016

4. Agarwal BB (2009) Informed consent-'da Vinci code' for our safety in empowered patient's safety. Surg Endosc 23(5):1158-1160

5. Agarwal BB, Chintamani AK, Goyal K, Mahajan KC (2012) Innovations in endosurgery-journey into the past of the future: to ride the SILS bandwagon or not? Indian J Surg 74(3):234-241

6. Agarwal N, Chintamani (2016) Cashless, tech-savvy future surgeon. Indian J Surg 78:171-172

7. Agarwal BB (2010) Umbilicus, navel, belly button-vitruvian guide for esthetic cosmetics: a Da Vinci code for beautiful informed consent. Surg Endosc 24(1):236-238

8. Agarwal BB (2009) Patient safety in laparoscopic cholecystectomy. Arch Surg 144(10):979

9. Agarwal BB, Sharma S (2010) Geek-speak on "peek port": hybridizing a hybrid technique not Geeks peak. Surg Endosc 24(1):232-233

10. Agarwal N (2016) Even handed future of surgery - ambidextrous, serious gamers with innate left hand laterality. Indian J Surg. doi:10.1007/s12262-016-1514-x

11. Agarwal BB (2010) Women in surgery. Arch Surg 145:210

12. Agarwal BB, Mahajan KC (2010) Laparoscopic biliary tract injury prevention: zero tolerance, error free performance. Surg Endosc 24(3):728-729

13. Agarwal BB (2010) Inguinal hernia repair-challenges beyond zero recurrence. Saudi J Gastroenterol 16(1):1-2

14. Reynolds W Jr (2001) The first laparoscopic cholecystectomy. JSLS 5(1):89-94

15. Wexner SD, Reissman P, Pfeifer J, Bernstein M, Geron N (1996) Laparoscopic colorectal surgery: analysis of 140 cases. Surg Endosc 10(2):133-136

16. Reissman P, Cohen S, Weiss EG, Wexner SD (1996) Laparoscopic colorectal surgery: ascending the learning curve. World J Surg 20(3):277-281

17. Agarwal BB, Chintamani AS (2015) Fast track surgery-minimizing side effects of surgery. Indian J Surg 77(Suppl 3):753-758

18. Yoo J (2008) Laparoscopic colorectal surgery. Perm J Winter 12(1): 27-31

19. Tran TB, Dua MM, Worhunsky DJ, Poultsides GA, Norton JA, Visser BC (2016) The first decade of laparoscopic pancreaticoduodenectomy in the United States: costs and outcomes using the nationwide inpatient sample. Surg Endosc 30(5):1778-1783

20. Place TL, Nau P, Mezhir JJ (2015) Minimally invasive pancreatectomy for cancer: a critical review of the current literature. J Gastrointest Surg 19(2):375-386

21. Heald RJ (1988) The 'holy plane' of rectal surgery. J R Soc Med 81(9):503-508

22. Croome KP, Farnell MB, Que FG, Reid-Lombardo KM, Truty MJ, Nagorney DM, Kendrick ML (2014) Total laparoscopic pancreaticoduodenectomy for pancreatic ductal adenocarcinoma: oncologic advantages over open approaches? Ann Surg 260(4):633-638

23. McMillan MT, Malleo G, Bassi C, Sprys MH, Vollmer CM Jr (2015) Defining the practice of pancreatoduodenectomy around the world. HPB (Oxford) 17(12):1145-1154

24. Agarwal BB, Gupta M, Agarwal S, Mahajan KC (2007) Laparoscopic cholecystectomy without using any energy source. J Laparoendosc Adv Surg Tech A 17(3):296-301

25. Agarwal BB, Gupta M, Agarwal S, Mahajan K (2007) Anatomical footprint for safe laparoscopic cholecystectomy without using any energy source: a modified technique. Surg Endosc 21(12):2154

26. Agarwal BB (2010) Results of laparoscopic cholecystectomy without energized dissection: a prospective study. Int J Surg 8(2):167172
27. Agarwal BB, Dhamija N, Manish K, Bethanbhatla MK, Muley KB, Jain R (2016) Dual laparoscopic cholecystectomies for dual primordium duplicate accessory gallbladder having independent cystic duct and artery. Surg Endosc

28. Agarwal BB, Agarwal S, Gupta M, Mahajan K (2008) Transaxillary endoscopic excision of benign breast lumps: a new technique. Surg Endosc 22(2):407-410

29. Agarwal BB, Manish K (2009) Endoscopic varicocelectomy by extraperitoneal route: a novel technique. Int J Surg 7(4):377-381

30. Agarwal BB, Gupta MK, Agarwal S, Mahajan KC (2008) Spontaneous rupture of iatrogenic (postinguinal herniorrhaphy) venovenous malformation managed endoscopically. J Laparoendosc Adv Surg Tech A 18(1):80-83

31. Fischer JE (2012) How to rescue general surgery. Am J Surg 204: 541-542

32. Black ME (2012) The bigger picture. Lest we forget. BMJ 345 , e8158

33. Kauffmann EF, Napoli N, Belluomini MA, Miccoli M, Brozzetti S, Boggi U (2015) Robot-assisted pancreaticoduodenectomy : safety and feasibility. Robot Surg Res Rev 2:65-71

34. McCormick F, Kadzielski J, Landrigan CP, Evans B, Herndon JH, Rubash HE (2012) Surgeon fatigue: a prospective analysis of the incidence, risk, and intervals of predicted fatigue-related impairment in residents. Arch Surg 147(5):430-435

35. Agarwal BB, Agarwal N, Agarwal KA, Goyal K, Nanvati JD, Manish K, Pandey H, Sharma S, Ali K, Mustafa ST, Gupta MK, Saluja S, Agarwal S (2014) Outcomes of laparoscopic cholecystectomy done with surgical energy versus done without surgical energy: a prospective-randomized control study. Surg Endosc 28(11):3059-3067

36. Agarwal BB, Nanavati JD, Agarwal N, Sharma N, Agarwal KA, Manish K, Saluja S, Agarwal S (2016) Biomolecular inflammatory response to surgical energy usage in laparoscopic surgery: results of a randomized study. Surg Endosc 30(5):1733-1741

37. Agarwal BB, Nanavati JD, Agarwal N, Sharma N, Murali K, Agarwal KA, Manish K, Saluja S, Agarwal S (2015) Role of energized dissection by the use of surgical energy in the observed functional liver damage during laparoscopic surgery - results of a prospective triple blind randomized study. CMRP 5:110-118

38. Kirman I, Cekic V, Poltoratskaia N, Sylla P, Jain S, Forde KA, Whelan RL (2005) Open surgery induces a dramatic decrease in circulating intact IGFBP-3 in patients with colorectal cancer not seen with laparoscopic surgery. Surg Endosc 19(1):55-59

39. Agarwal BB, Agarwal S (2007) The man-machine interface, a paradox of technology. Is the black box (BB) concept an angel or a demon? Surg Endosc 21(9):1680

40. Prigoff JG, Sherwin M, Divino CM (2016) Ethical Recommendations for video recording in the operating room. Ann Surg 264(1):34-35

41. Agarwal BB (2008) Journey of the carbon-literate and climateconscious endosurgeon having a head, heart, hands, and holistic sense of responsibility. Surg Endosc 22(12):2539-2540

42. Agarwal BB, Agarwal S (2008) Surgical pilgrimage - the need to avoid navigation through drains, medicine or 'medisin': our notes on NOTES. Surg Endosc 22(1):271-272

43. Agarwal BB (2009) Tattoo: a navigational tool, a lighthouse for biomolecular level precision in surgical endoscopy. Newton's apple or Eve's? Surg Endosc 23(5):1166-1167

44. Abcarian H (2016) Is the holy plane the last word? Dis Colon Rectum 59(2):160-161

45. Jha DN. Docs remove tumour without a cut. http://timesofindia. indiatimes.com/city/delhi/Docs-remove-tumour-without-acut/articleshow/49837615.cms

46. http://newsactive.biz/2016/04/22/american-college-of-surgeons-topublish-new-8220-because-i/. Accessed 21 Aug 2016

47. Li D, Xie K, Wolff R, Abbruzzese JL (2004) Pancreatic cancer. Lancet 363(9414):1049-1057 